\title{
Review-Innovative Polymeric Materials for Better Rechargeable Batteries: Strategies from CIC Energigune
}

\author{
Heng Zhang, ${ }^{1, z}$ Michel Armand, ${ }^{1, z}$ and Teófilo Rojo ${ }^{1,2, z}$ \\ ${ }^{1}$ CIC Energigune, Parque Tecnológico de Alava, Miñano, Alava 01510, Spain \\ ${ }^{2}$ Department of Chemical Engineering, Faculty of Science and Technology, University of the Basque Country \\ UPV-EHU, 48080 Bilbao, Spain
}

\begin{abstract}
The need for sustainable energy sources and their efficient utilization has motivated extensive explorations of new electrolytes, electrodes, and alternative battery chemistries departing from current lithium-ion battery (LIB) technologies. The evolution and development of rechargeable batteries are tightly linked to the research of polymeric materials, such as polymer electrolytes and redox-active polymeric electrodes, separators, and binders, etc... In this contribution, we review the recent progresses on polymer electrolytes and redox-active polymeric electrodes developed in CIC Energigune with particular attention paid to the molecular designing and engineering. On the basis of our knowledge and experience accumulated in rechargeable batteries, further developments and improvements on the properties of these polymeric materials for building better rechargeable batteries are discussed.

(C) The Author(s) 2019. Published by ECS. This is an open access article distributed under the terms of the Creative Commons Attribution Non-Commercial No Derivatives 4.0 License (CC BY-NC-ND, http://creativecommons.org/licenses/by-nc-nd/4.0/), which permits non-commercial reuse, distribution, and reproduction in any medium, provided the original work is not changed in any way and is properly cited. For permission for commercial reuse, please email: oa@electrochem.org. [DOI: 10.1149/2.0811904jes]
\end{abstract}

(c)) BY-NC-ND

Manuscript submitted January 14, 2019; revised manuscript received February 14, 2019. Published March 5, 2019. This was Paper 86 presented at the Cancun, Mexico, Meeting of the Society, September 30-October 4, 2018.

Electrochemical energy storage devices (e.g., electrochemical capacitors and batteries), being capable of storing electricity under a chemical form, are believed to be an increasingly important part of sustainable and efficient utilization toward renewable energy sources which is one of the main societal challenges to mankind in the $21 \mathrm{st}$ century. Amid the myriad of energy-storage technologies, rechargeable alkali metal-based batteries have captured extensive attention due to their high specific energy density and energy efficiency. ${ }^{1-3}$ The contemporary lithium-ion batteries (LIBs) possess a gravimetric/volumetric energy density (ca. $300 \mathrm{Wh} \mathrm{kg}^{-1}, 600 \mathrm{Wh} \mathrm{L}^{-1}$ ) six times higher than traditional lead-acid batteries (ca. $40 \mathrm{Wh} \mathrm{kg}^{-1}$, $100 \mathrm{Wh} \mathrm{L}^{-1}$ ), which not only empowers them to dominate the traditional markets of $3 \mathrm{C}$ electronics (i.e., computations, communication and cameras) and small portable devices (such as toys, garden tools, e-bikes, etc...) but also initiates the deployment of LIBs as power sources for pure electric (EV) and plug-in hybrid (PHV) vehicles in recent years. ${ }^{4-6}$ Besides, these high energy rechargeable batteries are emerging as powerful tools to store and regulate intermittent renewable energy (e.g., solar and wind) for the electric grids. ${ }^{3}$

The prevalent LIB technology, also known as "rocking chair battery", is built on the idea that the flow of $\mathrm{Li}^{+}$back and forth between two intercalation electrodes with different potentials proposed by $\mathrm{Ar}$ mand in the late 1970s. ${ }^{7}$ Seminal discoveries of lithium cobalt oxide $\left(\mathrm{LiCoO}_{2}, \mathrm{LCO}\right)$ as a positive electrode from Goodenough's laboratory ${ }^{8}$ and the petroleum coke as negative electrode by Yoshino et al. ${ }^{9}$ lead to the commercial application of LIBs by Sony in 1991. During the last 30 years, significant advances have been made in the development of LIBs, such as cost-effectiveness, cycle life, and power capabilities. However, the state-of-art LIB technologies still fall behind the stringent requirements of the newly emerging applications due to the following reasons: 1) the low specific capacities of graphite $(372 \mathrm{mAh}$ $\left.\mathrm{g}^{-1}, \mathrm{LiC}_{6}\right)$ and $\mathrm{LCO}$ electrodes $\left(140 \mathrm{mAh} \mathrm{g}^{-1}\right.$, at $\left.\mathrm{Li}_{0.5} \mathrm{CoO}_{2}\right)$ handicap the further improvement of energy density of LIBs $(<400 \mathrm{Wh}$ $\mathrm{kg}^{-1}$ ), which is crucial for remitting the "range-anxiety" of EVs and thereby remaining competitive against the fossil-fueled vehicles; 2) the low natural abundance of lithium (Li) and cobalt (Co) have highlighted risks in the raw-material supply availability for the massive implementation of LIBs, in particular, the shortage of Co may appear earlier than that of Li since Co is heavier (weights more in LIBs) and of similar rarity on Earth [i.e., crustal abundance: $25 \mathrm{ppm}(\mathrm{Co})$ vs. 20 ppm (Li); oceanic abundance: 0.02 ppb (Co) vs. 180 ppb (Li)]; $\left.{ }^{10} 3\right)$

zE-mail: hzhang@cicenergigune.com; marmand@ cicenergigune.com; trojo@cicenergigune.com the highly flammable carbonate solvents as electrolyte components in commercial LIBs raise severe safety concerns under abuse conditions, especially such liquid components are reactive and incompatible toward the next-generation high capacity alkali metal electrodes (e.g., $\mathrm{Li}$ or Na metal). ${ }^{11,12}$

Above-mentioned challenges of current LIB technologies urge the explorations of new electrolytes, electrodes, and alternative battery chemistries (e.g., Na-ion batteries, SIBs). ${ }^{12-26}$ Such evolution and development of rechargeable batteries have been tightly bonded to the research of polymeric materials, e.g., polymer electrolytes (PEs), redox-active polymeric electrodes, separators, binders, and so on. In particular, PEs and polymeric electrodes have emerged as promising candidates to substitute liquid electrolytes and inorganic electrode materials, respectively. ${ }^{27-29}$ This is due to the low cost of the organic precursors and the sustainability of their synthetic methods. Moreover, for polymeric materials, the existence of such a vast range of possible structures enables the proper tuning of structure-related properties according to the different cell chemistries of rechargeable batteries.

As a young research center in energy storage field with headquarters in the Basque Country, CIC Energigune has devoted continuous efforts on the research of innovative polymeric materials for improving the electrochemical performance of rechargeable batteries in the last years. As shown in Fig. 1, the developed polymeric materials have been integrated into rechargeable batteries as electrolytes and electrodes with intriguing properties, such as highly room temperature (RT) conductive PEs, single-ion conducting polysalts and

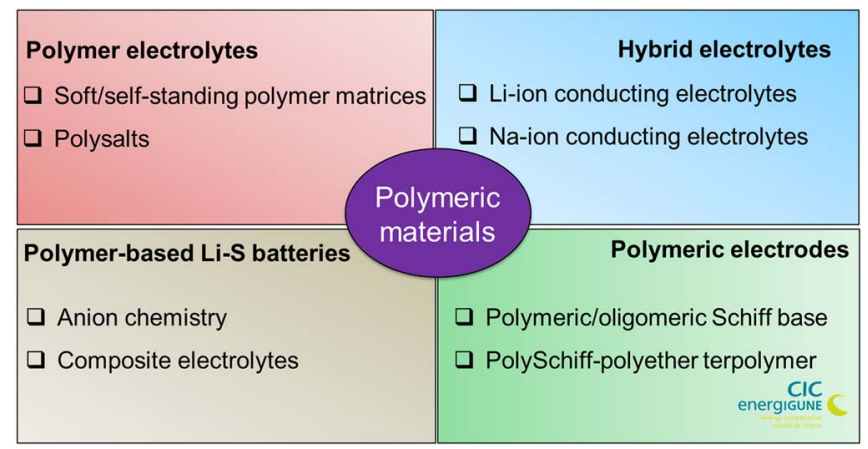

Figure 1. Polymeric materials developed in CIC Energigune for rechargeable batteries. 
composite/hybrid PEs, polymer-based all-solid-state lithium-sulfur batteries (ASSLSBs), and polymeric/oligomeric Schiff bases-based negative electrodes for SIBs. In this focus review, recent advances on PEs and polymeric electrodes developed in CIC Energigune are discussed, with particular attention paid to the molecular designing and engineering of these polymeric materials. Further developments and improvements on the properties of these polymeric materials for accessing safe and high-performance rechargeable batteries are presented.

\section{Advanced Polymer Electrolytes}

The increasing concerns in the safety of LIBs have incentivized the development of solid-state batteries where the liquid electrolytes are replaced with solid electrolytes [e.g., PEs or inorganic solid electrolytes (ISEs)]..$^{12,29-31}$ The utilization of PEs as metal-ion conducting electrolytes for rechargeable batteries was perceptively pointed out by Armand in $1978,{ }^{32}$ in view of the inherent flexibility of polymeric materials which could retain a good physical contact between electrode particles and electrolytes during charge/discharge process. The technological feasibility of polymer-based all-solid-state batteries is well demonstrated by the practical application of Bluecar and Bluebus commercialized by Bollore group, equipped with a $30 \mathrm{kWh} \mathrm{Li} \mathrm{metal}$ $\left(\mathrm{Li}^{\circ}\right) \|$ lithium iron phosphate $\left(\mathrm{LiFePO}_{4}, \mathrm{LFP}\right)$ battery pack. ${ }^{33}$

The widely used PEs comprise lithium bis(trifluorometha nesulfonyl)imide $\left\{\mathrm{Li}\left[\mathrm{N}\left(\mathrm{SO}_{2} \mathrm{CF}_{3}\right)_{2}\right]\right.$, LiTFSI $\}$ as conducting salt and poly(ethylene oxide) (PEO) as polymer matrix. The good chemical stability and structural flexibility of LiTFSI and strong solvating power of ethylene oxide $\left(-\mathrm{CH}_{2} \mathrm{CH}_{2} \mathrm{O}-\right.$, EO) endow LiTFSI/PEO electrolyte with good thermal stability and sufficient ionic conductivity at elevated temperature $\left(>70^{\circ} \mathrm{C}\right) .^{34,35}$ The thermal stability of LiTFSI/PEO electrolyte is such that it can be extruded in films at temperatures up to $250^{\circ} \mathrm{C}$, a major cost-cutting technology. ${ }^{36}$ Though LiTFSI/PEO electrolyte has been successfully implemented in Bluecars, several formidable challenges remain to be solved. Firstly, the ionic conductivity of LiTFSI/PEO electrolyte at RT is low $\left(<10^{-5} \mathrm{~S} \mathrm{~cm}^{-1}\right)$ due to the presence of crystalline phases below the melting point of PEO $\left(T_{\mathrm{m}}=65^{\circ} \mathrm{C}\right)$, which impedes the ionic transport in the amorphous phase. Such low ionic conductivity requires the batteries to be operated at a temperature significantly higher than RT (i.e., $>60^{\circ} \mathrm{C}$ ), which leads to a decreased energy density and efficiency due to the use of an extra thermal accessory/system. Secondly, the quality of the solid electrolyte interphase (SEI) layers formed between LiTFSI/PEO electrolyte and alkali metal negative electrodes is relatively low, which is responsible for the inferior cycling performances of the corresponding rechargeable batteries. ${ }^{37}$ Thirdly, the high mobility of anionic species in PEs with discrete anions (e.g., LiTFSI) causes large cell polarization upon charge/discharge. Though the main deleterious effect of concentration gradients, namely dendrites, has been considerably retarded in the Bluecar system by the ingenious use of a bi-gyroidal mixture of LiTFSI/PEO and poly(vinylidene fluoride) (PVDF) opposing a mechanical barrier to the growth of $\mathrm{Li}^{\circ}$ spikes, only relatively small areal capacities are attainable $\left(\approx 1 \mathrm{mAh} \mathrm{cm}^{-2}\right)$. The result is a lower specific energy and the current collector represents a higher fraction of the cell weight. ${ }^{29}$ Therefore, numerous attempts have been made on the molecular modification of PEO-based matrices and lithium salts to obtain highly cationic conducting PEs, such strategies are well scrutinized and discussed in recent reviews. ${ }^{29,34,35,38,39}$

Bearing in mind the importance of amorphicity and flexibility of polymer matrices on the ionic conductivity of PEs, we reported a series of comb-like, super-soft polymer matrices based on polyether side moieties (so-called Jeffamine) and poly(ethylene-alt-maleimide) backbones (Figs. 2a-2c). ${ }^{40}$ The high configurational freedoms and flexibility of propylene oxide/ethylene oxide units (PO/EO) effectively prevents the crytalization and thus confers the Jeffamine-based polymer matrices with low glass transition temperatures $\left(<-50^{\circ} \mathrm{C}\right)$ and high amorphicities. The poly(ethylene-alt-maleimide) backbones showed good chemical and thermal stabilities, and could be readily obtained through their commercial precursors poly(ethylene-alt-maleic anhydride) and mono aminated Jeffamines. The LiTFSI/Jeffaminebased PEs were fully amorphous at RT and outperformed the conventional LiTFSI/PEO electrolyte in terms of ionic conductivities at ambient temperature regions, e.g., $4.5 \times 10^{-5} \mathrm{~S} \mathrm{~cm}^{-1}$ (LiTFSI/Jeffaminebased electrolyte) vs. $8.0 \times 10^{-7} \mathrm{~S} \mathrm{~cm}^{-1}$ (LiTFSI/PEO) at RT. ${ }^{40}$ Coupling the Jeffamine-based polymer matrices with a SEI-favorable lithium salt, lithium bis(fluorosulfonyl)imide (LiFSI), ${ }^{37,41,42}$ the corresponding PEs were fully amorphous, highly conductive at RT, and electrochemically stable against a $\mathrm{Li}^{\circ}$ electrode. These exceptional properties enabled the operation of a full solid $\mathrm{Li}^{\circ} \| \mathrm{LiFePO}_{4}$ cell at RT (Fig. 2b). ${ }^{43}$

To improve the mechanical properties of Jeffamine-based polymers, we synthesized a family of Jeffamine-based block copolymers (Fig. 2c) containing the mechanically stiff polystyrene (PS) block which was employed by Balsara ${ }^{44,45}$ and Bouchet ${ }^{46,47}$ for increasing the mechianical strength of PEO-based electrolytes. In addition to our facile and "one-pot" synthetic routes, the resulting electrolytes exhibited good mechanical properties and high ionic conductivities (e.g., $7.9 \times 10^{-5} \mathrm{~S} \mathrm{~cm}^{-1}$ at $40^{\circ} \mathrm{C}$ ). The superior compatibility with $\mathrm{Li}^{\circ}$ electrode endowed a similar $\mathrm{Li}^{\circ} \| \mathrm{LiFePO}_{4}$ cell using the copolymer electrolytes to be cycled with good Coulombic efficiency and low capacity fading. ${ }^{48}$

As manifested above, high cationic/low anionic mobilities is of pivtal importance for enhancing the performance of polymerbased rechargeable batteries; therefore, we proposed two simple methods for imobilizing the anions and inceasing the cationic tranport numbers in PEs: grafting a negative charge delocalized anion (e.g., $\mathrm{CF}_{3} \mathrm{SO}_{2} \mathrm{~N}^{(-)} \mathrm{SO}_{2}$, TFSI-type anion) to either a polymer backbone ${ }^{49}$ or an inorganic nanoparticle. ${ }^{50-52}$ The polyacrylic acidbased polysalts were facilely prepared via the two-step reaction involving 1,10-carbonyldiimidazole (CDI) as a coupling reagent to attach the $\mathrm{CF}_{3} \mathrm{SO}_{2} \mathrm{~N}^{(-)} \mathrm{CO}-$ moieties. The blend of such polysalt with PEO gave a self-standing, single Li-ion conductive PE membrane with an ionic conductivity of $1.8 \times 10^{-5} \mathrm{~S} \mathrm{~cm}^{-1}$ at $80^{\circ} \mathrm{C}$. The $\mathrm{Li}^{\circ}$ $\| \mathrm{LiFePO}_{4}$ cell using the polysalt-based electrolyte showed moderate cycling performance for a few cycles, though abrupt cell failure was observed due to the high resistivity of electrolyte and SEI layer on $\mathrm{Li}^{\circ}$ negative electrode. ${ }^{49}$ On the other hand, tethering the TFSI-type anion to nano-sized aluminum oxide $\left(\mathrm{Al}_{2} \mathrm{O}_{3}\right)$ or silica $\left(\mathrm{SiO}_{2}\right)$ yielded a new type of nano-hybrid electrolyte with high cationic tranport number (Figs. $2 \mathrm{~d}$ and $2 \mathrm{e}$ ).$^{50-52}$ Both Li-ion and Na-ion conducting nanohybrid electrolytes showed single-ion behavior and high ionic conductivity when blended with PEO and poly(ethylene glycol) dimethylether (PEGDME). Such nano-hybrid electrolytes possessed high electrochemical and mechanical stability, enabling rechargable alkali metal batteries with long cycle life (Fig. 2f).

\section{Safe and High-Energy Polymer-Based Li-S Batteries}

The high gravimetric energy density, low cost, and environmental friendliness have spurred the research on Li-S batteries for lightweight applications (e.g., aircraft, drones artificial satellites, etc...) and large-scale stationary energy storage. ${ }^{53-57}$ As noted in several excellent reviews, ${ }^{11,53-58}$ the notorious $\mathrm{Li}^{\circ}$ dendrite formed during the continuous charge/discharge cycles causes low Coulombic/energy efficiency, internal short-circuit and subsequent thermal runaway, especially using a liquid solution of LiTFSI in 1,2dimethoxyethane/dioxolane (DME/DOL) which is highly volatile and flammable. Hence, the replacement of the liquid components, i.e., going from liquid to ASSLSBs, is essential for the safe utilization of such technology.

To identify the suitable solid electrolytes for fabricating highperformance ASSLSBs, we estimated the gravimetric/volumetric energy density of both polymer and ceramic-based Li-S batteries. ${ }^{57,59}$ As shown in Fig. 3a, the lower specific gravity of PEs compared to that of the ceramic-based ones (ca. $1.2 \mathrm{~g} \mathrm{~cm}^{-3}$ for PEO-based electrolytes vs. ca. $5 \mathrm{~g} \mathrm{~cm}^{-3}$ for garnet-type solid electrolytes) allows the polymer-based ASSLSBs to readily achieve gravimetric energy densities beyond the capability of the state-of-art LIBs $\left(>400 \mathrm{Wh} \mathrm{kg}^{-1}\right)$. 
(a)

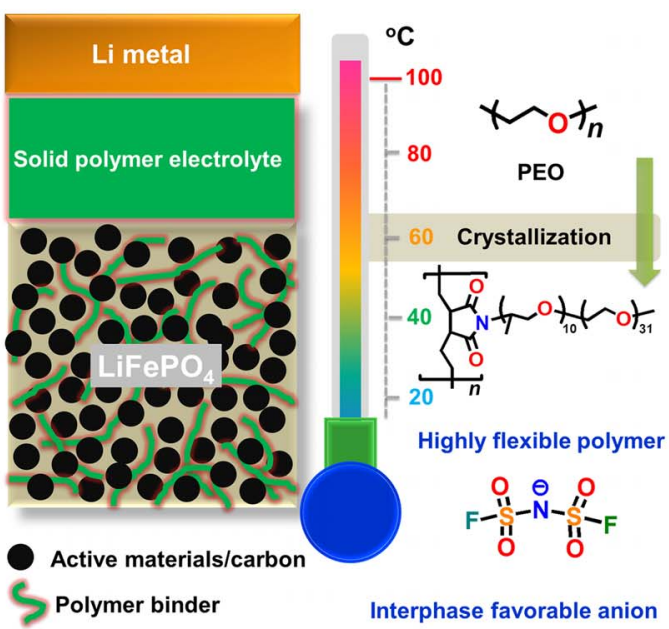

(c)

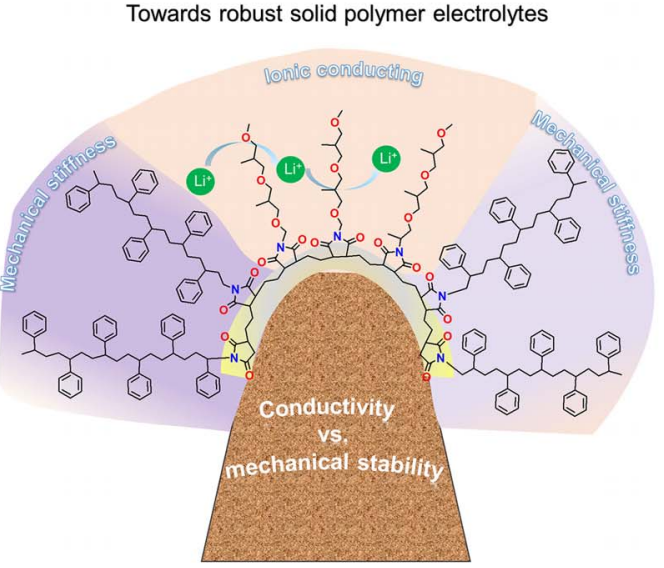

(b)
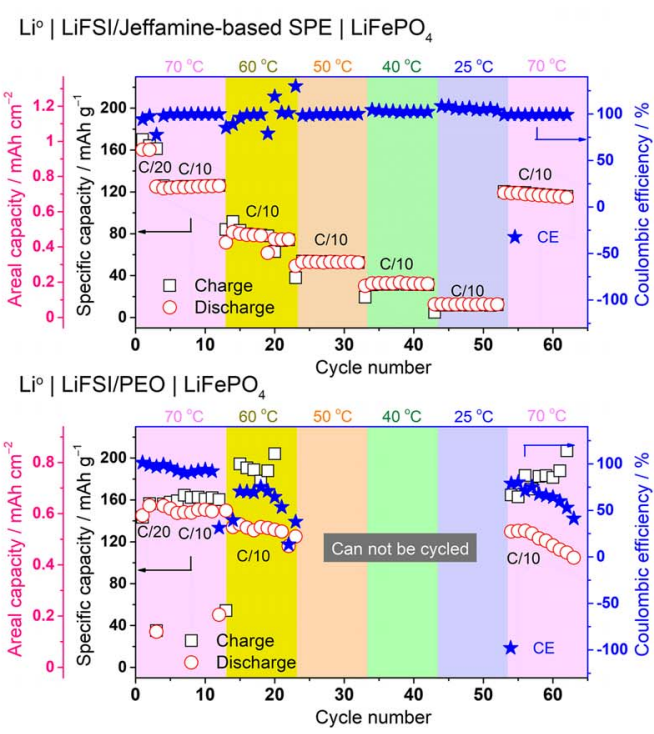

(d)

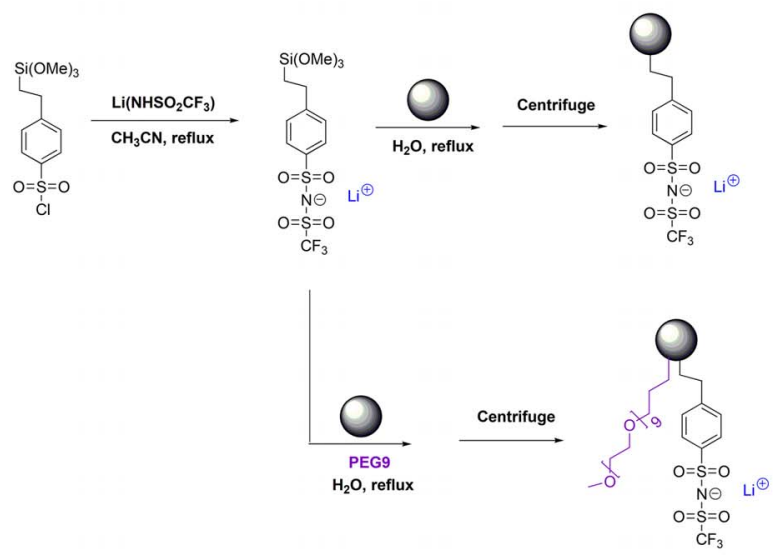

(e)

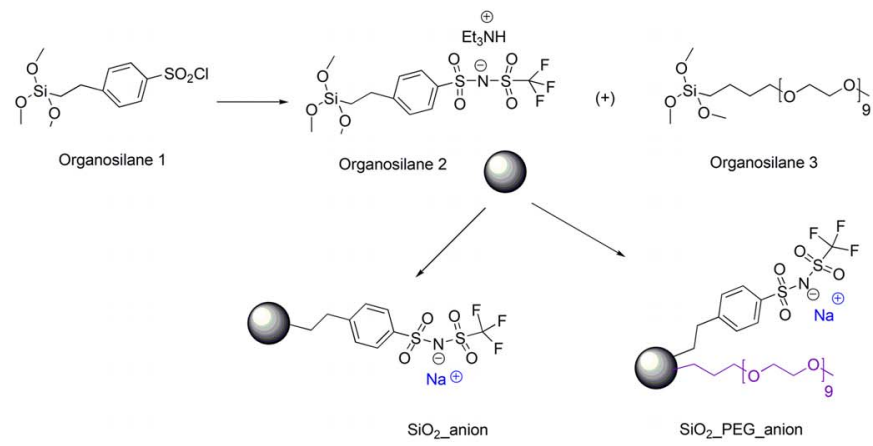

(f)

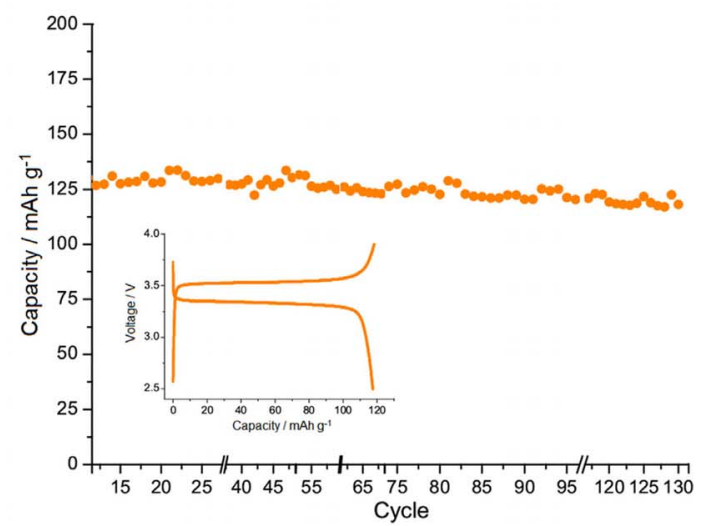

Figure 2. Advanced polymer electrolyte developed in CIC Energigune. (a) Jeffamine-based PEs in combination with SEI-favorable LiFSI salt for RT operation of all-solid-state $\mathrm{Li}^{\circ}$ polymer cells. (b) Cycling performance of the $\mathrm{Li}^{\circ} \| \mathrm{LiFePO}_{4}$ cells using $\mathrm{LiFSI} / \mathrm{Jeffamine}$-based (upper) and LiFSI/PEO-based SPEs (down) at various temperatures. Reproduced with permission from Ref. 43. (c) Self-standing highly conductive Jeffamine-based block copolymer electrolytes. Reproduced with permission from Ref. 48. (d, e) Synthetic route for Li-ion (d) and Na-ion (e) conducting nano-hybrid electrolytes. Reproduced with permission from Ref. 52 and Ref. 50, respectively. (f) Galvanostatic cycling of a $\mathrm{Li}^{\circ} \| \mathrm{LiFePO}_{4}$ cell using nano-hybrid electrolytes. Reproduced with permission from Ref. 52.

Though PEs tend to have lower RT ionic conductivities than ceramicbased electrolytes, their good interfacial contact with electrode materials, superior processability and scalability (e.g., ease in large-area, thin film preparation) are of utmost importance for the practical deployment of ASSLSBs in the future.
Taking the commercially available PEO as a benchmark polymer matrix, we conducted an in-depth analysis of the salt anion chemistry on the electrochemical performance of ASSLSBs. The substitution of LiTFSI with LiFSI resulted in a significantly improved cycling stability of Li-S cells due to the formation of stable and polysulfide 
(a)

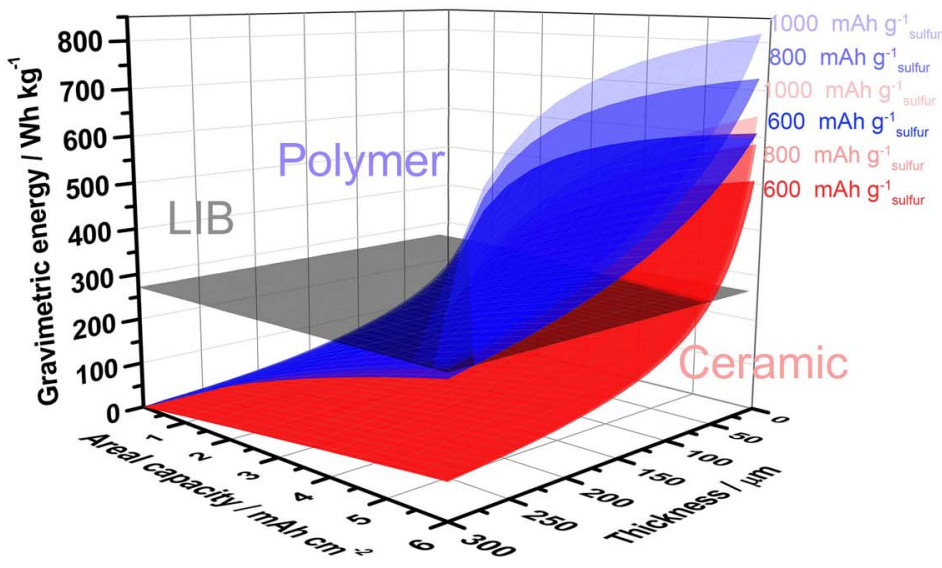

(c)
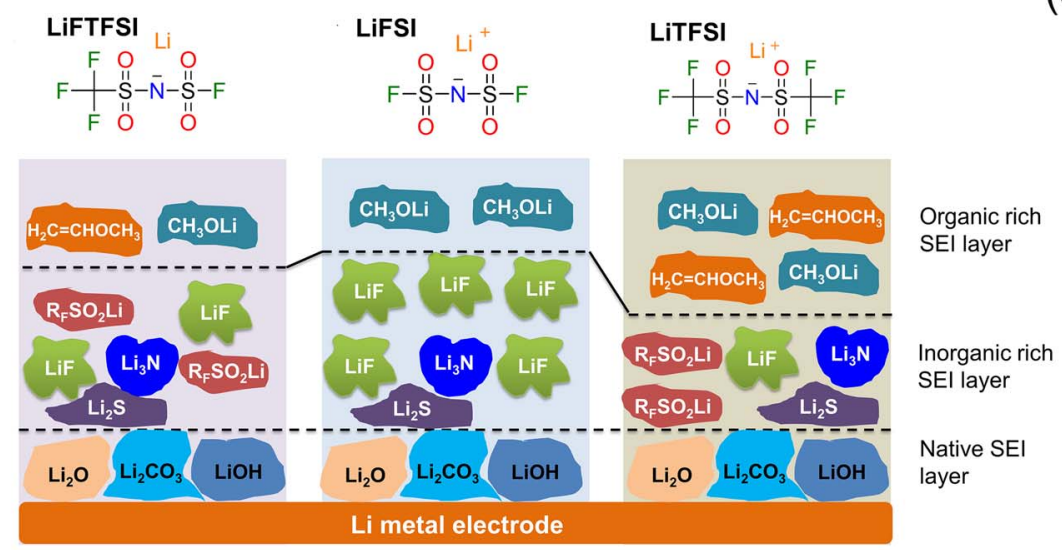

(b)

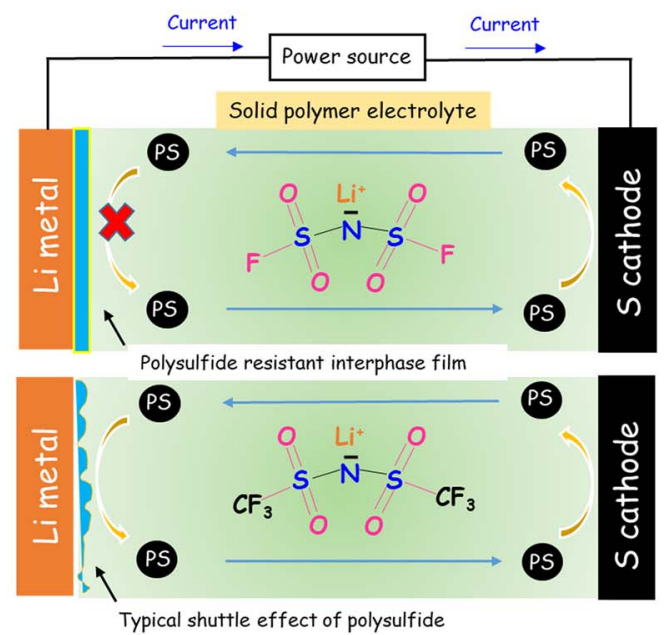

(d)

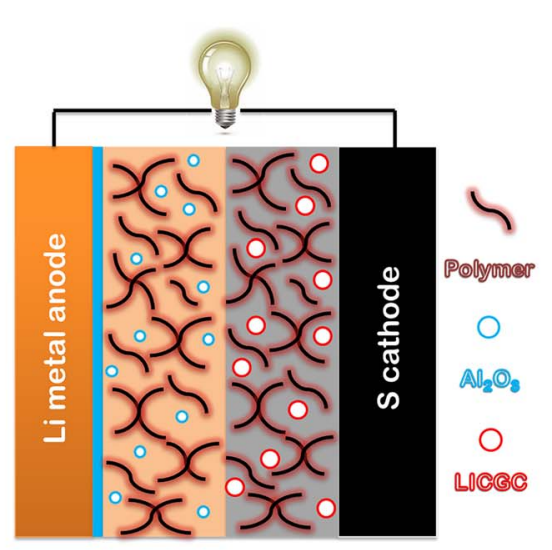

(e)

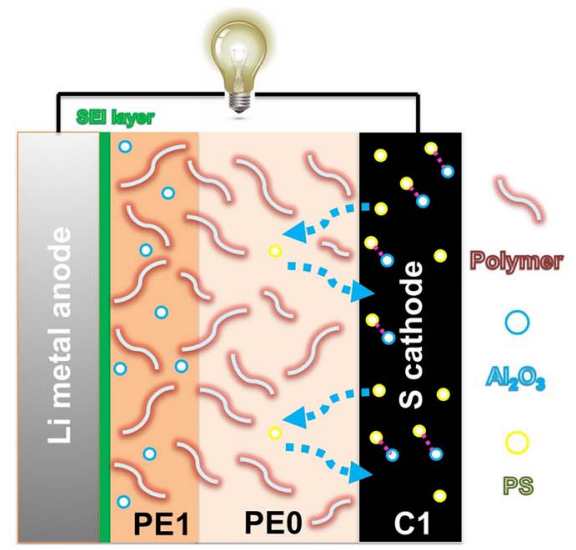

(f)

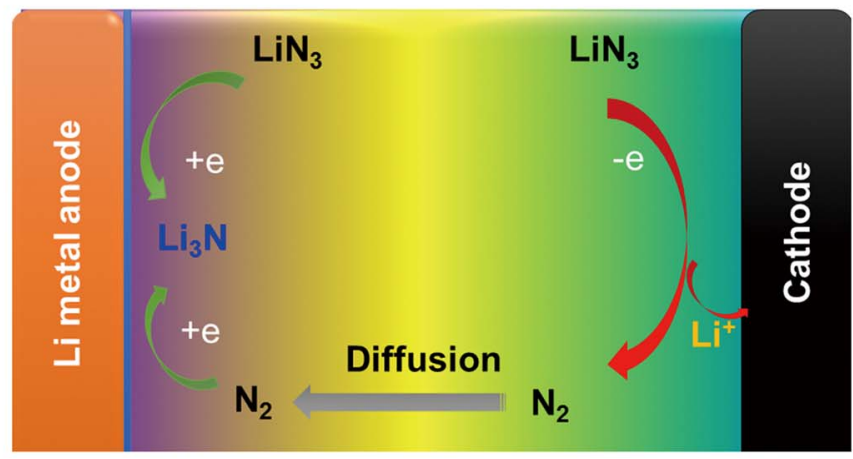

Figure 3. Safe and high-energy polymer-based Li-S batteries developed in CIC Energigune. (a) Estimated gravimetric energy density of Li-S cells in solid electrolytes with $60 \mathrm{wt} \% \mathrm{~S}$ content and various S utilizations. Reproduced with permission from Ref. 57. (b) The role of LiFSI/PEO and LiTFSI/PEO electrolyte in ASSLSBs. Reproduced with permission from Ref. 60. (c) Schematic illustration on the SEI layer formed on $\mathrm{Li}^{\circ}$ electrode in the LiFTFSI, LiFSI, and LiTFSI-based electrolytes. Reproduced with permission from Ref. 61. (d) Sketch of the cell with a bilayer electrolyte configuration ( $3 \mathrm{vol}_{\%} \mathrm{Al}_{2} \mathrm{O}_{3}$ - and $\mathrm{LICGC}$-based CPEs). Reproduced with permission from Ref. 64. (e) Schematic representation of $\mathrm{Al}_{2} \mathrm{O}_{3}$-added ASSLSBs, wherein C1, PE0, and PE1 are abbreviated for $\mathrm{Al}_{2} \mathrm{O}_{3}$-added S cathode, LiTFSI/PEO electrolyte, and $\mathrm{Al}_{2} \mathrm{O}_{3}$-added LiTFSI/PEO electrolyte, respectively. Reproduced with permission from Ref. 65. (f) Electrochemical reactions of $\mathrm{LiN}_{3}$ in rechargeable lithium-metal batteries. Reproduced with permission from Ref. 69.

(PS)-resistant SEI films in LiFSI-based PEs which prevented the side reactions of $\mathrm{PS}$ intermediates on $\mathrm{Li}^{\circ}$ negative electrode (Fig. 3b). ${ }^{60}$ Though LiFSI-based Li-S cell showed good Coulombic efficiency upon cycling; its specific capacity was generally lower than that of the LiTFSI-based one. Our very recent work revealed that $\mathrm{FSI}^{-}$could react chemically with PS species at RT via nucleophilic attack on the $\mathrm{S}-\mathrm{F}$ bond, generating an unstable trivalent anion which might decompose and irreversibly consume the electroactive materials (i.e., 
PS species), thus leading to a lower S utilization. Lately, we proposed a new salt anion, (fluorosulfonyl)(trifluoromethanesulfonyl)imide anion $\left\{\left[\mathrm{N}\left(\mathrm{SO}_{2} \mathrm{~F}\right)\left(\mathrm{SO}_{2} \mathrm{CF}_{3}\right)\right]^{-}, \mathrm{FTFSI}^{-}\right\}$for ASSLSBs, in light of the molecular level combination of $-\mathrm{SO}_{2} \mathrm{CF}_{3}$ (belongs to $\mathrm{TFSI}^{-}$) and $-\mathrm{SO}_{2} \mathrm{~F}$ (belongs to $\mathrm{FSI}^{-}$) functionalities (Fig. 3c). ${ }^{61}$ The passivation layer generated from LiFTFSI-based electrolyte was more stable and conductive compared to that from LiFSI- and LiTFSI-based ones, and LiFTFSI reacted reversibly with the polysulfide species formed during the cycling. These merits conferred the LiFTFSI-based Li-S cell an ultrahigh $\mathrm{S}$ utilization, good Coulombic efficiency, and superior rate capability (e.g., $1394 \mathrm{mAh} \mathrm{g}_{\text {sulfur }}{ }^{-1}$ and $1.2 \mathrm{mAh} \mathrm{cm}^{-2}$ at the first cycle). These results strongly suggest the importance of the molecular structure of lithium salts in ASSLSBs.

Besides the screening of new lithium salts, we investigated the role of both inactive and active inorganic fillers on the cell performance of ASSLSBs. Early work from Scrosati et al. ${ }^{62,63}$ evidenced the positive effect of the incorporation of nano-sized $\mathrm{Al}_{2} \mathrm{O}_{3}$ in PEs (also called composite polymer electrolytes, CPEs), e.g., increased mechanical stability and ionic conductivity, decreased interfacial resistivity and so on. We observed that the addition of nano-sized $\mathrm{Al}_{2} \mathrm{O}_{3}$ fillers in LiFSI/PEO did not increase the ionic conductivity nor the Li-ion transference number, but remarkably enhanced the chemical and electrochemical stability of $\mathrm{Li}^{\circ}$ electrode/electrolyte interface, ${ }^{42}$ resulting in a high Coulombic efficiency of the corresponding $\mathrm{Li}-\mathrm{S}$ cell greater than $99 \%{ }^{64}$ However, in the presence of $\mathrm{Al}_{2} \mathrm{O}_{3}$ nanoparticles, the cell delivered much lower areal/specific capacity than the reference one, mainly ascribed to the absorbance of solubilized PS species on $\mathrm{Al}_{2} \mathrm{O}_{3}$ nanoparticles, leading to the detachment of PS species from conductive carbon in the cathode and thereby a reduced discharge capacity. ${ }^{64}$ On the contrary, embedding Li-ion conducting glass ceramic (LICGC) in LiFSI/PEO electrolyte increased the sulfur utilization and areal capacity but caused a poor cycling stability due to the side reaction of LICGC with $\mathrm{Li}^{\circ}$ negative electrode. Therefore, we proposed a bilayer electrolyte configuration where the $\mathrm{Al}_{2} \mathrm{O}_{3}$-added membrane facing $\mathrm{Li}^{\circ}$ negative electrode and LICGC-added membrane contacting S cathode (Fig. 3d). Clearly, the cell delivered a good areal capacity of $0.53 \mathrm{mAh} \mathrm{cm}-2$ with Coulombic efficiency higher than $99 \%$ at the end of 50 cycles. $^{64}$ Interestingly, if adding the nano-size $\mathrm{Al}_{2} \mathrm{O}_{3}$ in the PEs as negative electrode stabilizer and at the same time in the $\mathrm{S}$ cathode as $\mathrm{PS}$ reservoir, as well as separating $\mathrm{Al}_{2} \mathrm{O}_{3}$-added membrane and $\mathrm{Al}_{2} \mathrm{O}_{3}$-added $\mathrm{S}$ cathode with a filler-free electrolyte membrane (Fig. 3e), the Li-S cell reached a high areal capacity of $0.85 \mathrm{mAh} \mathrm{cm}^{-2}$ after 30 cycles with good cycling stability. ${ }^{65}$

Last but not the least, despite the huge effort on the development of the electrolyte additives, little attention has been paid to introduce functional solid additives to PEs. ${ }^{66}$ We reported lithium azide $\left(\mathrm{LiN}_{3}\right)$ as a novel lithium nitride $\left(\mathrm{Li}_{3} \mathrm{~N}\right)$ precursor for forming a compact and conductive passivation layer on $\mathrm{Li}^{\circ}$ negative electrode (Fig. 3f), ${ }^{69}$ since $\mathrm{Li}_{3} \mathrm{~N}$ is highly ionic conductive (e.g., $6 \times 10^{-3} \mathrm{~S} \mathrm{~cm}^{-1}$ at RT for the single-crystal structure ${ }^{67}$ ) and is thermodynamically stable against $\mathrm{Li}^{\circ}$ negative electrode. ${ }^{68}$ The SEI layer formed on $\mathrm{Li}^{\circ}$ negative electrode in the presence of $\mathrm{LiN}_{3}$ was uniform, dendrite-free, and rich in $\mathrm{Li}_{3} \mathrm{~N}$, which boosted the $\mathrm{Li}$ \% electrolyte interfacial stability, leading to the enhancement of cyclability, Coulombic/energy efficiencies and discharge capacity in the Li-S cells.

In a brief summary, the optimization of electrolyte recipe could significantly regulate the electrochemical behavior of PEs and thereby enabling the development of safe and high-performance ASSLSBs.

\section{Redox-active Polymeric Materials for Na-Ion Batteries}

The key raw materials such as $\mathrm{Li}$ and Co used in current LIBs are confronting a foreseeable shortage due to their low natural abundance. ${ }^{70}$ Under such circumstances, Na-based technologies including Na-ion batteries, RT Na-S and $\mathrm{Na}-\mathrm{O}_{2}$ batteries have emerged with flourishing research activities in recent years because of the considerably higher overall abundance and ubiquitous distribution of $\mathrm{Na}$ on earth. ${ }^{12-26}$ For example, the estimated crustal and oceanic abundances of $\mathrm{Na}$ are $2.4 \times 10^{4} \mathrm{ppm}$ and $1.8 \times 10^{4} \mathrm{ppm}$, respectively, both of which are over 1000 times higher than those of Li (i.e., 20 $\mathrm{ppm}$ in crust and $180 \mathrm{ppb}$ in ocean for $\mathrm{Li}$ ). ${ }^{10}$ In addition, for $\mathrm{Na}$ based technologies, the rare $\mathrm{Ni}$ - and Co-based positive electrodes could be replaced with the abundant $\mathrm{Fe}$ - or Mn-based oxides, which are much more environmentally friendly and cost-effective. Recently, Hu's group clearly demonstrated the technological feasibility of Nabased batteries by implementing SIBs as power source for a low-speed $\left(<70 \mathrm{~km} \mathrm{~h}^{-1}\right)$, low-cost EV. The battery pack was built with pyrolyzed anthracite (PA) as negative electrode and air-stable $\mathrm{Cu}$-based layered oxide of $\mathrm{O} 3-\mathrm{Na}_{0.9}\left[\mathrm{Cu}_{0.22} \mathrm{Fe}_{0.30} \mathrm{Mn}_{0.48}\right] \mathrm{O}_{2}$ as positive electrode. ${ }^{71-73}$

Since 2011, CIC Energigune has been dedicating continuous efforts to the material designing and engineering of Na-based batteries, aiming at increasing their energy density, cycle life and costeffectiveness. ${ }^{13,17,19,21,23,74-76}$ Organic electrodes especially polymeric electrodes provide several intrinsic advantages over the inorganic ones: 1) the wide structural diversity and flexibility of redox-active polymeric materials offers the possibility of tuning structure-related properties according to different requirements (e.g., flexibility, redox potentials, specific capacity, etc...);2) the abundance of these organic materials, possibly in biomass, leads to a potential low-cost synthesis with good scalability; and 3) the absence of toxic heavy metals such as $\mathrm{Co}, \mathrm{Ni}, \mathrm{V}$ enables easier disposal and recycling procedures. The redoxactive organic materials as negative electrode for SIBs reported previously were mainly carboxylates (e.g., disodium terephthalate ${ }^{77-79}$ and benzenediacrylate ${ }^{80}$ ), since the discovery of dilithium terephthalate $\left(\mathrm{Li}_{2} \mathrm{C}_{8} \mathrm{H}_{4} \mathrm{O}_{4}\right)$ and lithium trans, trans-muconate $\left(\mathrm{Li}_{2} \mathrm{C}_{6} \mathrm{H}_{4} \mathrm{O}_{4}\right)$ salts as negative electrode for LIBs by Armand et al. in 2009. ${ }^{81}$ Other organic electrodes with N/O-containing functionalities have been investigated but their operation voltage are higher than $1 \mathrm{~V}$ vs. $\mathrm{Na}^{+} / \mathrm{Na}$, e.g., disodium pyromellitic diimidate, ${ }^{82}$ indigo carmine,${ }^{83}$ 2,5-disodium-1,4benzoquinone,${ }^{84}$ pteridine-based compounds, ${ }^{85}$ and so on.

Recently, we proposed several redox-active polymeric and oligomers Schiff $\left(\mathrm{R}^{1} \mathrm{HC}=\mathrm{NR}^{2}\right)$ bases as negative electrodes for SIBs. ${ }^{16}$ These electroactive polymeric Schiff bases were prepared by a clean and simple condensation reaction between non-conjugated aliphatic or conjugated aromatic diamine block with a terephthalaldehyde unit (Fig. 4a). The wide palette of the available structures allowed the regulation of the redox potential and specific capacity of Schiff base based negative electrodes. For example, the conjugated aromatic linker was found to improve the electrical conductivity and thereby leading to a better electrochemical activity compared to the non-conjugated ones; and the polymeric Schiff bases containing $\mathrm{CH}=\mathrm{N}-\mathrm{Ar}-\mathrm{N}=\mathrm{HC}-$ instead of $-\mathrm{N}=\mathrm{CH}-\mathrm{Ar}-\mathrm{CH}=\mathrm{NC}-$ was electrochemically inactive due to the loss of conjugation. Reversible capacities of ca. $350 \mathrm{mAh} \mathrm{g}^{-1}$ were achieved for unsubsituted poly[ $N, N^{\prime}$-p (benzylidene)phenylenediamine], corresponding to $1.4 \mathrm{Na}^{+}$ions per $\mathrm{C}=\mathrm{N}$ moieties in the polymeric chain. ${ }^{16}$

In spite of the good electrochemical performance of polymeric Schiff bases, their low solubility in organic solvents causes poor processability via the typical solution lamination process, and their low electronic conductivity requires the addition of large amount of conductive carbon and thereby resulting in a lower energy density. Hence, we further prepared a family of polySchiff/oligoether terpolymers containing diaminated Jeffamine moieties in the polymer backbone, as shown in Fig. $4 b{ }^{25}$ Owing to the high configurational freedom and the strong affinity to polar organic solvents of the Jeffamine units, the modified terpolymers showed an increased the electrolyte uptake and strengthened adhesion to the current collector, enabling the lamination of the electrode without the addition of extra binder. The polySchiff/oligoether terpolymers showed a reversible capacity of 185 $\mathrm{mAh} \mathrm{g}^{-1}$ as the binder-free laminated electrodes with $20 \mathrm{wt} \%$ carbon. Besides, these polymeric materials acted as redox-active binders for replacing the conventional PVDF binder, as indicated by the good cycling performance of the negative electrode using hard carbon as electroactive material.

Lastly, we reported various crystalline oligomeric Schiff bases with carboxylate end groups, in hope of hybridizing the redox activity of Schiff base and carboxylate family which has high capacity and good processability. ${ }^{18}$ As shown in Fig. 4c, these oligomeric Schiff bases 
(a)<smiles>[Z]c1cc(C=O)c([Z])cc1C=O</smiles>
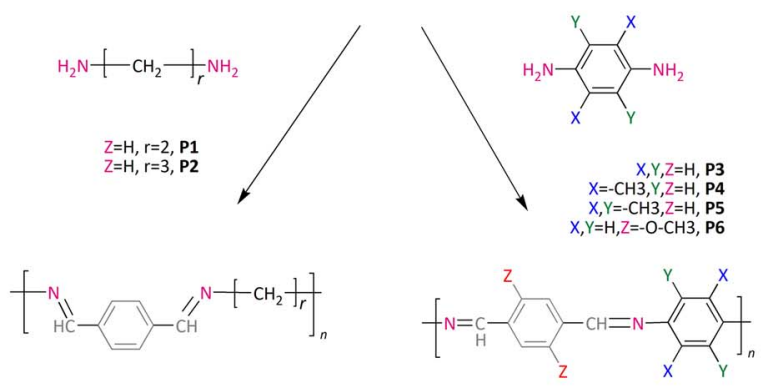

(b)
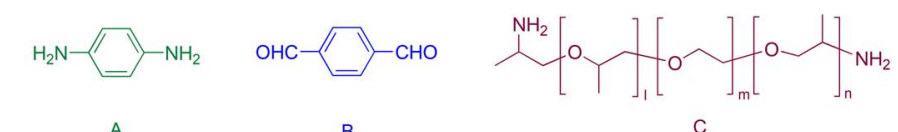

B

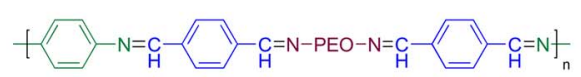

$P$

(c)

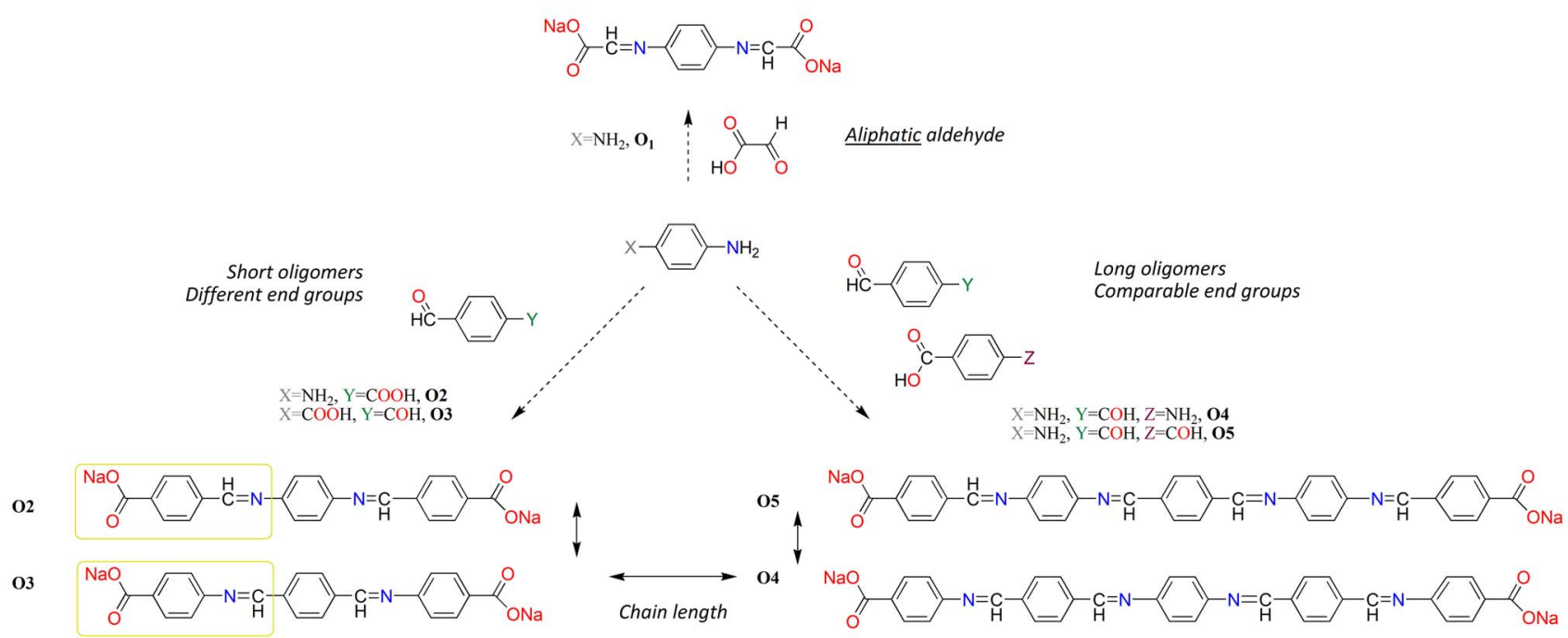

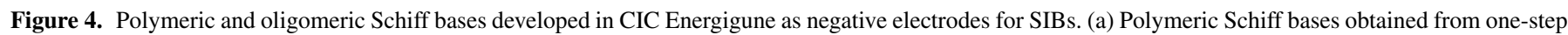

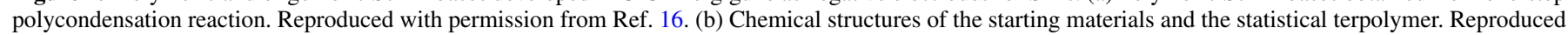

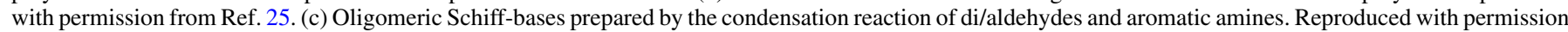
from Ref. 18.

were prepared from the aromatic amines and aldehydes by simple condensation reaction. The feasibility of oligomeric Schiff bases as negative electrodes for SIBs was confirmed by their high specific capacity $\left(\sim 340 \mathrm{mAh}^{-1}\right)$ and good capacity retentions. Using DFT calculations, we determined that $-\mathrm{OOC}-\mathrm{Ar}-\mathrm{CH}=\mathrm{N}-$ and $-\mathrm{N}$ $=\mathrm{CH}-\mathrm{Ar}-\mathrm{CH}=\mathrm{N}$ - were the "active" Hückel co-planar units for $\mathrm{Na}^{+}$insertion, and the reversible capacity were related to the ratio between active/total Hückel units. Interestingly, the specific capacity was highly related to the configuration of azomethine groups with respect to end carboxylate groups, and $-\mathrm{OOC}-\mathrm{Ar}-\mathrm{CH}=\mathrm{N}-$ showed higher capacity than - OOC $-\mathrm{Ar}-\mathrm{N}=\mathrm{CH}-$. Overall, polymeric and oligomeric Schiff bases are interesting organic electrodes for $\mathrm{Na}$ based batteries.

\section{Conclusions}

The versatile chemical structures of polymeric materials offer a fertile playground for tuning their nature and properties according to the cell chemistries of rechargeable batteries. In the last years, we developed various functional, innovative polymeric materials for building safe, low-cost rechargeable batteries, encompassing 1) highly RT conductive PEs, single-ion conducting polysalts, and composite/hybrid PEs; 2) polymer-based ASSLSBs evidencing the role of the anion in SEI formation and PS shuttle control; and 3) polymeric and oligomeric Schiff base-based negative electrodes for SIBs application. These ma- terials are promising candidates as either robust electrolytes or redoxactive electrodes for future applications. On the basis of our knowledge and experience accumulated in rechargeable batteries, we anticipate that several aspects could be further strengthened:

1) Jeffamine-based polymers are interesting candidates for RT operation of polymer-based batteries. Grafting Jeffamine moieties to polymer backbone or nano-sized inorganic particles might confer the electrolytes with single-ion conducting behavior as well as high ionic mobility. It is worth mentioning that, in addition to the regulation of bulk properties of PEs (e.g., glass transition, ionic conductivity, mechanical properties, etc...), the assessment of new PEs needs to be tightly related to the interfacial compatibility of PEs/electrode, since the ionic transport across the interphases governs the overall performance of rechargeable batteries.

2) The anion chemistries and electrolyte additives play a peculiar role in dictating the nature of SEI layer formed on $\mathrm{Li}^{\circ}$ electrode. However, the areal loading of $\mathrm{S}$ cathode is still low $(<1.5 \mathrm{mAh}$ $\mathrm{cm}^{-2}$ ), rational design and engineering of the $S$ cathode, including type and morphology of conductive carbon, architectural design of the electrode, could be beneficial for further improving the energy density of the polymer-based Li-S batteries.

3) The electrochemical activities of polymeric/oligomeric Schiff bases as negative electrodes for SIBs are impressive compared 
to other types of organic electrodes. Though these redox-active polymeric materials are environmentally friendly, cost-effective and ease to dispose/recycle; the specific capacity of Schiff basesbased SIBs are close to that of the best conventional negative electrodes (e.g., hard carbon) but they need more nano-carbon additives because of their relatively lower electronic conductivity. The operating voltage is also more positive than that of hard carbons, but this is an advantage to avoid $\mathrm{Na}^{\circ}$ plating during operation. Further modifications of the chemical structures of the redox-active polymeric materials with high atomic efficiency in terms of electrochemical characteristics (e.g., capacity, voltage) are still possible.

With continuous efforts in these fields, we believe that the enormous possibilities in customizing electroactive polymeric materials would ultimately leads to their implementation in practical highperformance rechargeable batteries in the future.

\section{Acknowledgments}

This work was supported by GV-ELKARTEK-2016 from the Basque Government, and MINECO RETOS (Ref: ENE2015-64907C2-1-R) from Spanish Government. H.Z. thanks the Basque Government for the Berrikertu program (1-AFW-2017-2). This manuscript is dedicated to the 73th birthday of Prof. Dr. Michel Armand, who ushered theoretical concepts leading to practical applications in energyrelated electrochemistry.

\section{ORCID}

\section{Heng Zhang (DD https://orcid.org/0000-0002-8811-6336}

\section{References}

1. J.-M. Tarascon and M. Armand, Nature, 414, 359 (2001).

2. M. Armand and J.-M. Tarascon, Nature, 451, 652 (2008).

3. B. Dunn, H. Kamath, and J.-M. Tarascon, Science, 334, 928 (2011).

4. N. Nitta, F. Wu, J. T. Lee, and G. Yushin, Mater. Today, 18, 252 (2015).

5. G. E. Blomgren, J. Electrochem. Soc., 164, A5019 (2016).

6. J. B. Goodenough, Nat. Electron., 1, 204 (2018).

7. M. B. Armand, in Materials for Advanced Batteries, p. 145, Springer (1980).

8. K. Mizushima, P. C. Jones, P. J. Wiseman, and J. B. Goodenough, Mater. Res. Bull. 15, 783 (1980)

9. A. Yoshino, K. Sanechika, and T. Nakajima, "Secondary battery," U.S. Pat. 4,668,595, 26 May (1987)

10. https://education.jlab.org/itselemental/index.html.

11. X.-B. Cheng, R. Zhang, C.-Z. Zhao, and Q. Zhang, Chem. Rev., 117, 10403 (2017).

12. C. Zhao, L. Liu, X. Qi, Y. Lu, F. Wu, J. Zhao, Y. Yu, Y.-S. Hu, and L. Chen, Adv Energy Mater, 8, 1703012 (2018).

13. K. B. Hueso, M. Armand, and T. Rojo, Energy Environ. Sci., 6, 734 (2013),

14. M. D. Slater, D. Kim, E. Lee, and C. Johnson, Adv. Funct. Mater, 23, 947 (2013).

15. H. Kang, Y. Liu, K. Cao, Y. Zhao, L. Jiao, Y. Wang, and H. Yuan, J. Mater. Chem. A 3, 17899 (2015).

16. E. Castillo-Martínez, J. Carretero-González, and M. Armand, Angew. Chem., 53, 5341 (2014).

17. M. H. Han, E. Gonzalo, G. Singh, and T. Rojo, Energy Environ. Sci., 8, 81 (2015).

18. M. López-Herraiz, E. Castillo-Martínez, J. Carretero-González, J. Carrasco, T. Rojo, and M. Armand, Energy Environ. Sci., 8, 3233 (2015).

19. I. Landa-Medrano, C. Li, N. Ortiz-Vitoriano, I. Ruiz de Larramendi, J. Carrasco, and T. Rojo, J. Phys. Chem. Lett., 7, 1161 (2016).

20. H. Che, S. Chen, Y. Xie, H. Wang, K. Amine, X.-Z. Liao, and Z.-F. Ma, Energy Environ. Sci., 10, 1075 (2017)

21. K. B. Hueso, V. Palomares, M. Armand, and T. Rojo, Nano Res., 10, 4082 (2017)

22. J.-Y. Hwang, S.-T. Myung, and Y.-K. Sun, Chem. Soc. Rev., 46, 3529 (2017).

23. N. Ortiz-Vitoriano, N. E. Drewett, E. Gonzalo, and T. Rojo, Energy Environ. Sci., 10, 1051 (2017)

24. G. Åvall, J. Mindemark, D. Brandell, and P. Johansson, Adv. Energy Mater, 8, 1703036 (2018).

25. N. Fernández, P. Sánchez-Fontecoba, E. Castillo-Martínez, J. Carretero-González, T. Rojo, and M. Armand, ChemSusChem, 11, 311 (2018).

26. Y. Xu, M. Zhou, and Y. Lei, Mater. Today, 21, 60 (2018).

27. P. Novák, K. Müller, K. S. V. Santhanam, and O. Haas, Chem. Rev., 97, 207 (1997)

28. S. Muench, A. Wild, C. Friebe, B. Haupler, T. Janoschka, and U. S. Schubert, Chem Rev., 116, 9438 (2016).

29. H. Zhang, C. Li, M. Piszcz, E. Coya, T. Rojo, L. M. Rodriguez-Martinez, M. Armand, and Z. Zhou, Chem. Soc. Rev, 46, 797 (2017).

30. J. Janek and W. G. Zeier, Nat. Energy, 1, 16141 (2016).
31. X. Judez, G. G. Eshetu, C. Li, L. M. Rodriguez-Martinez, H. Zhang, and M. Armand, Joule, 2, 2208 (2018).

32. M. B. Armand, J. M. Chabagno, and M. J. Duclot, The $2^{\text {nd }}$ International Conference on Solid Electrolyte.St. Andrews, (1978).

33. http://www.bollore.com/en-us/activities/electricity-storage-and-solutions/blueapplications

34. M. Armand, Annu. Rev. Mater. Res., 16, 245 (1986).

35. Z. Xue, D. He, and X. Xie, J. Mater. Chem. A, 3, 19218 (2015).

36. G. B. Appetecchi, S. Scaccia, and S. Passerini, J. Electrochem. Soc., 147, 4448 (2000).

37. H. Zhang, C. Liu, L. Zheng, F. Xu, W. Feng, H. Li, X. Huang, M. Armand, J. Nie, and Z. Zhou, Electrochim. Acta, 133, 529 (2014).

38. V. Di Noto, S. Lavina, G. A. Giffin, E. Negro, and B. Scrosati, Electrochim. Acta, 57, 4 (2011).

39. D. T. Hallinan and N. P. Balsara, Annu. Rev. Mater. Res., 43, 503 (2013).

40. I. Aldalur, H. Zhang, M. Piszcz, U. Oteo, L. M. Rodriguez-Martinez, D. Shanmukaraj, T. Rojo, and M. Armand, J. Power Sources, 347, 37 (2017).

41. H. Zhang, C. Liu, L. Zheng, W. Feng, Z. Zhou, and J. Nie, Electrochim. Acta, 159, 93 (2015)

42. X. Judez, M. Piszcz, E. Coya, C. Li, I. Aldalur, U. Oteo, Y. Zhang, W. Zhang, L. M. Rodriguez-Martinez, H. Zhang, and M. Armand, Solid State Ionics, 318, 95 (2018).

43. I. Aldalur, M. Martinez-Ibañez, M. Piszcz, L. M. Rodriguez-Martinez, H. Zhang, and M. Armand, J. Power Sources, 383, 144 (2018)

44. D. T. Hallinan, S. A. Mullin, G. M. Stone, and N. P. Balsara, J. Electrochem. Soc., 160, A464 (2013)

45. R. Yuan, A. A. Teran, I. Gurevitch, S. A. Mullin, N. S. Wanakule, and N. P. Balsara, Macromolecules, 46, 914 (2013).

46. R. Bouchet, T. N. T. Phan, E. Beaudoin, D. Devaux, P. Davidson, D. Bertin, and R. Denoyel, Macromolecules, 47, 2659 (2014)

47. D. Devaux, D. Glé, T. N. T. Phan, D. Gigmes, E. Giroud, M. Deschamps, R. Denoyel, and R. Bouchet, Chem. Mater, 27, 4682 (2015).

48. I. Aldalur, M. Martinez-Ibañez, M. Piszcz, H. Zhang, and M. Armand, Batteries \& Supercaps (2018).

49. M. Piszcz, O. Garcia-Calvo, U. Oteo, J. M. Lopez del Amo, C. Li, L. M. Rodriguez-Martinez, H. B. Youcef, N. Lago, J. Thielen, and M. Armand, Electrochim. Acta 255, 48 (2017)

50. I. Villaluenga, X. Bogle, S. Greenbaum, I. Gil de Muro, T. Rojo, and M. Armand, J. Mater. Chem. A, 1, 8348 (2013).

51. M. Armand, I. Villaluenga, and T. Rojo Aparicio, "Hybrid electrolytes provided with inorganic nanoparticles covalently grafted with organic anions" EP Pat. 20120382290 19 July (2012).

52. N. Lago, O. Garcia-Calvo, J. M. Lopez del Amo, T. Rojo, and M. Armand, ChemSusChem, 8, 3039 (2015)

53. P. G. Bruce, S. A. Freunberger, L. J. Hardwick, and J.-M. Tarascon, Nat. Mater., 11, 19 (2012)

54. Y. X. Yin, S. Xin, Y. G. Guo, and L. J. Wan, Angew. Chem., 52, 13186 (2013).

55. L. F. Nazar, M. Cuisinier, and Q. Pang, MRS Bull., 39, 436 (2014)

56. R. Cao, W. Xu, D. Lv, J. Xiao, and J.-G. Zhang, Adv. Energy Mater, 5, 1402273 (2015).

57. X. Judez, H. Zhang, C. Li, G. G. Eshetu, J. A. González-Marcos, M. Armand, and L. M. Rodriguez-Martinez, J. Electrochem. Soc., 165, A6008 (2018).

58. Z. W. Seh, Y. Sun, Q. Zhang, and Y. Cui, Chem. Soc. Rev., 45, 5605 (2016).

59. C. Li, H. Zhang, L. Otaegui, G. Singh, M. Armand, and L. M. Rodriguez-Martinez, J. Power Sources, 326, 1 (2016).

60. X. Judez, H. Zhang, C. Li, J. A. González-Marcos, Z. Zhou, M. Armand, and L. M. Rodriguez-Martinez, J. Phys. Chem. Lett., 8, 1956 (2017).

61. G. G. Eshetu, X. Judez, C. Li, M. Martinez-Ibañez, I. Gracia, O. Bondarchuk, J. Carrasco, L. M. Rodriguez-Martinez, H. Zhang, and M. Armand, J. Am. Chem. Soc., 140, 9921 (2018).

62. F. Croce, G. B. Appetecchi, L. Persi, and B. Scrosati, Nature, 394, 456 (1998).

63. F. Croce, L. Persi, F. Ronci, and B. Scrosati, Solid State Ionics, 135, 47 (2000).

64. X. Judez, H. Zhang, C. Li, G. G. Eshetu, Y. Zhang, J. A. Gonzalez-Marcos, M. Armand, and L. M. Rodriguez-Martinez, J. Phys. Chem. Lett., 8, 3473 (2017).

65. X. Judez, G. G. Eshetu, I. Gracia, P. López-Aranguren, J. A. González-Marcos, M. Armand, L. M. Rodriguez-Martinez, H. Zhang, and C. Li, ChemElectroChem (2018).

66. H. Zhang, G. G. Eshetu, X. Judez, C. Li, L. M. Rodriguez-Martínez, and M. Armand, Angew. Chem., 57, 15002 (2018).

67. U. V. Alpen, A. Rabenau, and G. H. Talat, Appl. Phys, Lett., 30, 621 (1977).

68. Y. Zhu, X. He, and Y. Mo, Adv. Sci., 4, 1600517 (2017).

69. G. G. Eshetu, X. Judez, C. Li, O. Bondarchuk, L. M. Rodriguez-Martinez, H. Zhang, and M. Armand, Angew. Chem., 56, 15368 (2017).

70. E. A Olivetti, G. Ceder, G. G. Gaustad, and X. Fu, Joule, 1, 229 (2017).

71. Y. Li, Y.-S. Hu, X. Qi, X. Rong, H. Li, X. Huang, and L. Chen, Energy Storage Mater., 5, 191 (2016).

72. http://www.hinabattery.com/en/index.php?catid=15.

73. http://wls.iphy.ac.cn/emagazine/news.php?id=25141.

74. V. Palomares, P. Serras, I. Villaluenga, K. B. Hueso, J. Carretero-Gonzalez, and T. Rojo, Energy Environ. Sci., 5, 5884 (2012).

75. V. Palomares, M. Casas-Cabanas, E. Castillo-Martinez, M. H. Han, and T. Rojo, Energy Environ. Sci., 6, 2312 (2013).

76. M. A. Munoz-Marquez, D. Saurel, J. L. Gomez-Camer, M. Casas-Cabanas, E. Castillo-Martinez, and T. Rojo, Adv. Energy Mater, 7, 1700463 (2017).

77. A. Abouimrane, W. Weng, H. Eltayeb, Y. Cui, J. Niklas, O. Poluektov, and K. Amine, Energy Environ. Sci., 5, 9632 (2012). 
78. Y. Park, D.-S. Shin, S. H. Woo, N. S. Choi, K. H. Shin, S. M. Oh, K. T. Lee, and S. Y. Hong, Adv. Mate., 24, 3562 (2012).

79. L. Zhao, J. Zhao, Y.-S. Hu, H. Li, Z. Zhou, M. Armand, and L. Chen, Adv. Energy Mater, 2, 962 (2012).

80. V. A. Mihali, S. Renault, L. Nyholm, and D. Brandell, RSC Adv., 4, 38004 (2014).

81. M. Armand, S. Grugeon, H. Vezin, S. Laruelle, P. Ribière, P. Poizot, and J. M. Tarascon, Nat. Mater., 8, 120 (2009).
82. S. Renault, V. A. Mihali, K. Edström, and D. Brandell, Electrochem. Commun., 45 52 (2014).

83. M. Yao, K. Kuratani, T. Kojima, N. Takeichi, H. Senoh, and T. Kiyobayashi, Sci. Rep., 4, 3650 (2014).

84. B. E. Gurkan, Z. Qiang, Y.-M. Chen, Y. Zhu, and B. D. Vogt, J. Electrochem. Soc., 164, H5093 (2017).

85. J. Hong, M. Lee, B. Lee, D.-H. Seo, C. B. Park, and K. Kang, Nat. Commun., 5, 5335 (2014). 